\title{
Synergistic effects of dual parasitism in Daphnia magna under nutrient limitation
}

\author{
Lien Reyserhove *, Koenraad Muylaert, \\ Isabel Vanoverberghe \& Ellen Decaestecker
}

\author{
Department of Biology, KU Leuven Campus Kortrijk, Kulak, Belgium. \\ ${ }^{*}$ Corresponding author: Lien.Reyserhove@ $@$ kuleuven.be
}

\begin{abstract}
Human-induced increases in the bioavailability of carbon (C), nitrogen $(\mathrm{N})$ and phosphorus $(\mathrm{P})$ have the potential to alter the context for host-parasite dynamics in aquatic ecosystems. Given that both eutrophication and infectious diseases are becoming more prominent, it is essential to disentangle the factors that determine virulence expression in keystone grazers. Here, we focus on the impact of nutrient limitation in single versus dual parasite exposure in the water flea Daphnia magna (Crustacea, Branchiopoda). For this, we fed specimens of D. magna with algae differing in C:N:P ratios and exposed them to two virulent parasites, Pasteuria ramosa (bacteria) and the agent causing White Fat Cell (WFCD, unknown classification), both in single and dual parasite exposure treatments. Exposure to the two parasites synergistically reduced host survival, mainly driven by WFCD exposure, especially under severe nutrient limitation. Under these conditions individuals of D. magna began reproducing earlier, which resulted in a higher reproductive output upon dual parasite exposure. We here discuss these results within the framework of host stress responses, nutrient allocation and energy budgets, and conclude that the way food quality interferes with host-parasite interactions varies, depending on the parasite species involved, the nutrient requirements of all actors and the trait investigated.
\end{abstract}

KEYWORDS. Energy allocation, food quality, host-parasite, synergism.

Reyserhove L., Muylaert K, Vanoverberghe I. \& Decaestecker E. 2017. Synergistic effects of dual parasitism in Daphnia magna under nutrient limitation. Belgian Journal of Zoology 147 (1): 61-76. https://doi.org/10.26496/ bjz.2017.5

\section{Introduction}

Natural populations in food webs are strongly regulated by consumers such as parasites, but also bottom-up by food abundance and quality (LAFFERTY et al. 2008; PRESTON \& JOHNSON 2010; AALTO et al. 2015). Host and parasite traits are sensitive to environmental factors such as food availability and quality, which interact to affect parasite virulence levels (FELLOUS \& KOELLA 2009; VALE et al. 2013; DUNCAN et al. 2014). The outcome of the interaction between host and parasite depends on the amount of energy available for the host, the allocation of this energy towards life history responses, and the need and capacity of the parasite to exploit this (SMITH \& Holt 1996; BedHOMME et al. 2004; PEDERSON \& FENTON 2007; MIDEO 2009; CRESSLER et al. 2014). In general, parasite virulence is expected to increase upon nutrient limitation of the host, due to increased resource competition between both antagonists (FERGUSON \& READ 2002; LAMBREChTS et al. 2006; Frost et al. 2008; CORNET et al. 2014). Resource 
availability will also affect (especially costly) host immune defenses (OJALA et al. 2005; KAPARI et al. 2006; Klemola et al. 2007; LiTTLE \& KillicK 2007), especially if there is a metabolic link between their resources, given that host immunity and parasites then interact as "competitors" (CRESSLER et al. 2014). On the other hand, a parasite that is not efficient in stealing nutrients from its host may also show a reduced growth rate, which is then reflected in lower virulence levels (EBERT et al. 2004; SEPPÄLA et al. 2008; ABU KWAIK \& BUMANN 2013; CORNET et al. 2014).

In most cases, multiple infections will be more virulent than single infections, given that the most competitive strains gain a disproportional share of the host (BEN-AMI et al. 2011; SCHMID-HEMPEL 2011; ALIZON et al. 2013; GRIFFITHS et al. 2015). However, the net outcome of multiple infections depends, inter alia, on the mode of competition between different parasite species, the involvement of the host immune system (GRAHAM 2008; MideO 2009; CRESSLER et al. 2014), host demography (IZHAR et al. 2015) and the environmental dependency of multiple infections (PENCZYKOWSKI et al. 2016). In multiple infections, the combined negative effect of the parasites will depend on whether the parasites require nutrients essential to the host. Also, the type of interaction between the parasites will be important: antagonistic interactions between parasites can decrease virulence, while a reciprocal facilitation could synergistically lead to increased virulence levels (ESWARAPPA et al. 2012; AALTO et al. 2015).

In freshwater aquatic ecosystems, biochemical and elemental composition of natural seston fluctuates considerably and affects food web dynamics (SøNDERGAARD et al. 1999; DE SENERPONT DOMIS et al. 2013), for instance via the microbial community (ELSER et al. 1995; COTNER et al. 2010; PONCE-SOTO et al. 2015), but also via zooplankton performance in terms of reproduction, mortality, growth rate and community composition (STERNER et al. 1993; VERREYDT et al. 2012; SARPE et al. 2014). For instance, the keystone grazer Daphnia (Crustacea, Branchiopoda) requires a sufficient amount of $\mathrm{P}$ to invest in P-rich ribosomal RNA (rRNA), which is needed for protein synthesis and growth (ElSER et al. 2000, 2003). Nutrient deprivation will also affect trade-offs between life history traits, e.g., prolonging life span, but at the cost of reproduction (BOGGS 2009; PIETRZAK et al. 2010).

A shortage of energy and elements impacts the interaction of Daphnia with its parasites (FROST et al. 2008; Hall et al. 2009; Dallas \& DraKe 2014; Aalto et al. 2015; DeCAESTECKER et al. 2015). In natural systems, parasitism of Daphnia individuals is the rule rather than the exception, with multiple infections occurring frequently (DECAESTECKER et al. 2005; EBERT 2005; WOLINSKA et al. 2009; JANSEN et al. 2010; LANGE et al. 2014). Because of their tight association, parasites can compete for nutrients with their host (FROST et al. 2008; HALL et al. 2009). We here investigate how severe food deprivation impacts the virulence of single versus multiple parasite exposure in Daphnia magna (Straus, 1820). More in particular, we performed a laboratory experiment in which we infected individuals of Daphnia magna with the bacterium Pasteuria ramosa and the infectious agent that causes White Fat Cell Disease (EBERT 2005; COOPMAN 2014), both in a single species and multiple species infection. These infected hosts were then fed with food of different $\mathrm{C}: \mathrm{N}: \mathrm{P}$ ratios, in order to monitor how changing food quality impacts host-parasite interactions. We focussed on algal C:N:P ratio as this is known to induce P-limitation in Daphnia (ACHARYA et al. 2004), but the tested effect can also be impacted by food quality in general, as a high N:P ratio correlates with other food parameters such as digestibility and PUFA (poly-unsaturated fatty acids) content.

\section{Material and methods}

\section{Daphnia genotypes and parasites}

The Daphnia magna genotypes in our experiment (clones OM2 10.20, 12.1, 22.11, 25.10, 25.6) were from a shallow pond (Oude Meren 2, 'Abdij van 't Park', Heverlee, Belgium, 5051' N, 04²43' E). The parasites used in this experiment were Pasteuria ramosa and the agent causing White Fat Cell Disease (WFCD). P. ramosa is a horizontally transmitted parasite infecting the hemolymph, causing chronic 
REYSERHOVE L. et al., Multiple parasitism and food limitation

TABLE 1

Elemental composition of the algal (Scenedesmus obliquus) cultures.

\begin{tabular}{|c|c|c|c|c|c|c|}
\hline & \multicolumn{3}{|c|}{ Elemental concentration $(\mathbf{m g} / \mathbf{L})$} & \multicolumn{3}{c|}{ Elemental ratio (molar) } \\
\hline Culture & $\mathbf{N}$ & $\mathbf{P}$ & $\mathbf{C}$ & $\mathbf{N}: \mathbf{P}$ & $\mathbf{C : N}$ & $\mathbf{C : P}$ \\
\hline 1 & 1.56 & 0.137 & 59.22 & 26 & 22 & 575 \\
\hline 2 & 6.07 & 0.121 & 103.86 & 114 & 9.75 & 1136 \\
\hline
\end{tabular}

infections, resulting in a sterilized Daphnia sp. host individual (EBERT 2005). Feeding individuals of Daphnia sp. with P-deprived food induces increased virulence of $P$. ramosa (FROST et al. 2008). WFCD is a small coccoid parasite that infects the adipose tissue of Daphnia species (EBERT 2005). The infection is transmitted horizontally, and severely impacts survival in Daphnia species (COOPMAN et al. 2014; LANGE et al. 2014) and to a lesser extent fecundity upon disease progression. P. ramosa strains were isolated from the same pond as were the Daphnia clones, but from a later time (2012) than the clones were isolated (most recent clone isolates 2002). WFCD strains were isolated from a shallow pond in Zonhoven, Belgium (lake 21, 50 59'12.72" N and $5^{\circ} 0^{\prime} 35.56^{\prime \prime} \mathrm{E}$ ) and have been cultured in $\mathrm{OM} 2$ clones during a field season (180 L outdoor mesocosms).

\section{Algal elemental ratio in the experimental set-up}

The green alga Scenedesmus obliquus (Kützing, 1833; Chlorophyta, Chlorophyceae) was grown in semi-continuous batch cultures (dilution rate $0.1 \mathrm{~d}^{-1}$ ). We used artificial WC-medium in which all nutrient concentrations were reduced tenfold to simulate mesotrophic conditions (except for $\mathrm{NaNO}_{3}$ and $\mathrm{K}_{2} \mathrm{HPO}_{4} \cdot 3 \mathrm{H}_{2} \mathrm{O}$ ). The P-concentration in the medium was kept constant $\left[\mathrm{K}_{2} \mathrm{HPO}_{4}=0.2 \mathrm{mg} / \mathrm{L}\right]$ and the $\mathrm{N}$-concentration was raised (from \pm 1.5 to $\pm 12 \mathrm{mg} / \mathrm{L}$ with resulting molar N:P ratios of 16 and 128) to induce differences in $\mathrm{C}: \mathrm{N}: \mathrm{P}$ ratios. An N:P ratio of 128 in chemostats has previously been used to induce severe P-limitation in Daphnia (STERNER et al. 1993; ACHARYA et al. 2004). These food quality treatments were not chosen to mimic the natural environment of the Daphnia individuals, but rather to generate a gradient ranging from low to extreme food limitation. By manipulating the absolute $\mathrm{N}$ content rather than decreasing $\mathrm{P}$ in the medium, we aimed to induce severe food limitation in the Daphnia (rather than solely implementing P-limitation), as both a high absolute N-concentration and high N:P ratio have been shown to be detrimental for Daphnia (Frost et al. 2008; DALlAS \& DRAKE 2014). For each $S$. obliquus culture, we measured the algal C, N and P-content. Aliquots of algal suspension were filtered over pre-ignited Whatman GF/F filters. These filters were kept dry at $60^{\circ} \mathrm{C}$ before analysis. $\mathrm{P}$ and $\mathrm{N}$-concentrations of $S$. obliquus were determined via persulfate digestion followed by molybdateascorbic acid colorimetry using a microflow technicon ${ }^{\mathrm{TM}}$ segmented flow analysis system (Quaatro, Seal Analytical). We determined C-content on the same filters by dividing algal dry weight (measured as in DECLERCK et al. 2007) by two (assumption of 50\% carbon content of algal dry weight). The absolute concentrations and elemental ratios for $\mathrm{C}, \mathrm{N}$ and $\mathrm{P}$ are given in Table 1. As the optimal elemental ratio for Daphnia ranges between 100-200 for C:P and 12-28 for N:P (ANDERSEN \& HESSEN 1991; HeSSEN \& LYCHE 1991; ElSER et al. 2000; Frost et al. 2006; JEYASHINGH et al. 2009, but see DEMOTT \& VAN DONK 2013), we can say that nutrient limitation was present in both algal cultures. However, nutrient limitation was stronger in algal culture 2, apparent from the high (but still realistic, STERNER 2008) $\mathrm{C}: \mathrm{P}$ and $\mathrm{N}: \mathrm{P}$ ratios clearly indicating strong P-limitation. However, although these algal ratios strongly suggest nutrient limitation, we cannot exclude the possibility that other food quality parameters such as PUFA content and digestibility might affect the Daphnia. Therefore, we now refer to the effect of "food quality / limitation / deprivation" rather than "nutrient limitation / deprivation". To standardize the amount fed (based on C-concentration) to the individuals of D. magna, we measured the algal C-content spectrophotometrically (Hach Lange DR 2800) using a calibration curve for each S. obliquus culture. These curves were established by measuring the optical density at $750 \mathrm{~nm}$ of the algal suspension with known C-concentration. 


\section{Experimental set-up}

After hatching, the D. magna genotypes were kept as stock cultures under standardized conditions $\left(20^{\circ} \mathrm{C} \pm 2{ }^{\circ} \mathrm{C}, 16 / 8 \mathrm{~h}\right.$ day / night cycle) and were fed ad libitum with $S$. obliquus. For each genotype (five genotypes in total), we grew five separate maternal lines. Each maternal line was kept for at least two generations in the laboratory before the start of the experiment. At the first day of the experiment, one-day old juveniles were transferred to $80 \mathrm{ml}$ jars, with a total of five juveniles per jar. Each jar contained one individual for each genotype. As it has been shown that there are strong genotype $\mathrm{x}$ genotype interactions with respect to Daphnia - P. ramosa interactions (CARIUS et al. 2001; DECAESTECKER et al. 2007, 2013; METZGER et al. 2016), we pooled five genotypes in one experimental jar to overcome such specific host-genotype - parasite strain interactions with respect to infectivity, given that the main interest of this study was on virulence effect. By pooling different genotypes, the chance of infection is higher and as such there is a higher chance of variation in the virulence effect. In total, 80 experimental jars were set up (four parasite treatments $\times$ two food quality treatments $\times$ ten replica per treatment combination). All experimental replicas contained the same combination of these five particular genotypes. Because of this, and because of the fact that it was impossible to identify a particular genotype on a visual basis, Daphnia genotype could not be included in the statistical analysis. From the first day of the experiment, all D. magna individuals were given a $2 \mathrm{mg} \mathrm{C} / \mathrm{L}$ algal solution of the corresponding food ratio. All cultures were refreshed every other day, except when infections were initiated. At day four of the experiment, infections were initiated. For this, we transferred all D. magna individuals to a volume of $40 \mathrm{~mL}$ to maximize spore uptake. To obtain the spore suspensions for each parasite, cadavers of $D$. magna individuals (infected with WFCD or P. ramosa) were homogenized mechanically by using a pestle. This homogenized tissue, containing spores of the specific parasite species (WFCD or P. ramosa), was then added to their respective experimental jars to initiate the infections (WFCD, P. ramosa or the combined parasite treatment). To exclude food effects of adding the homogenized Daphnia tissue, the placebo (no parasite) treatment was initiated by exposing the D. magna individuals to homogenized cadavers of healthy, uninfected Daphnia individuals. Each of the experimental treatments received an equal amount of homogenized (infected or uninfected) Daphnia tissue.

Spore concentrations of $P$. ramosa in this homogenized tissue were estimated with a counting chamber ( $0.1 \mathrm{~mm}$ depth, Bürker counting chamber) using phase-contrast microscopy at $400 \times$ magnification. For the $P$. ramosa and the combined parasite treatment, we chose an infection dose of 75000 P. ramosa spores per $D$. magna individual to ensure a very high infection rate (REGOES et al. 2003). The causative agent of WFCD, presumably a virus (Ebert and Tönshoff, personal communication), can hardly be detected under a light microscope, which makes it impossible to determine spore loads of this parasite. Therefore, to initiate the WFCD and combined parasite treatment, we used one homogenized D. magna cadaver, infected with WFCD, to infect three experimental individuals. During the first three days of the parasite exposure, the amount of medium was kept low (gradually increasing from $20 \mathrm{~mL}$ to $40 \mathrm{~mL}$ ). Jars were not refreshed for four days and were stirred daily to maximize spore uptake by D. magna individuals. After 33 days, Daphnia mortality in all experimental treatments was very high and the experiment was terminated. Survival and reproduction (time to first clutch and the total number of juveniles produced per jar) of D. magna individuals were monitored daily.

\section{Prediction of joint effects of parasites}

Interactions between P. ramosa and WFCD were tested by comparing predicted and observed effects of the combined treatment. Combined parasite effects were estimated based on the single parasite treatment effects according to Equation 1 (based on the model by BLISS 1939, see also COORS \& DE MEESTER 2008).

$$
\mathrm{E}_{\text {mix }}=1-\Pi^{\mathrm{i}}\left(1-\mathrm{E}_{1}\right) \quad \mathrm{E}_{\text {mix }}=1-\Pi^{\mathrm{i}}\left(1-\mathrm{E}_{1}\right) \quad \text { Eqn } 1
$$


$\mathrm{E}_{\text {mix }}$ represents the estimated combined effect of the parasites, while $\mathrm{E}_{\mathrm{i}}$ stands for the effect of the single stressor $i$. $\mathrm{E}_{\mathrm{i}}$ represents a transformed value of the observed value $\mathrm{e}_{\mathrm{i}}$ for the single stressor based on Equation 2.

$$
\mathrm{E}_{\mathrm{i}}=\frac{\left(\mathrm{c}_{\mathrm{i}}-\mathrm{c}_{\text {control }}\right)}{\left(\mathrm{c}_{\max }-\mathrm{c}_{\text {control }}\right)} \quad \mathrm{E}_{\mathrm{i}}=\frac{\left(\mathrm{c}_{\mathrm{i}}-\mathrm{c}_{\text {control }}\right)}{\left(\mathrm{c}_{\max }-\mathrm{c}_{\text {control }}\right)} \quad \text { Eqn 2 }
$$

$e_{i}$ is the value of the single stressor treatment, while $e_{\max }$ represents the value of the maximum possible effect for the single stressor. In the case of D. magna survival, this value was 0 . For the number of juveniles produced, the maximum possible effect was defined based on the range of the data. The maximum number of juveniles produced here was set at $\mathrm{e}_{\max }=15$. Parasites were considered to act as synergistically or antagonistically, when the predicted values were outside the range of $2 \times \mathrm{SE}$ of the observed effect (based on COORS \& DE MEESTER 2008).

\section{Statistical analysis}

In all analyses, the food-treatment effect was expressed as 'limited' versus 'extremely limited'. Both the parasite ("P" in Table 2) and food limitation ("FQ" in Table 2) effect were considered as factorial variables. Survival was analyzed in two different ways. First we performed an overarching survival analysis using recordings of all time points (survival was monitored on each day of the experiment), using a Cox proportional hazards model with the $\operatorname{coxph}()$ specification in $\mathrm{R}$. This analysis was performed to relate the time that passed before death to changes in food quality and parasitism, and to account for individuals that survived up until the end of the experiment. All explanatory variables were considered to be static (i.e. their impact did not change over time; DUNEAU et al. 2012; DUFFY et al. 2015). This analysis predicts the relative risk of death for each D. magna individual, which is inversely correlated with the linear predictor (LP) value used here for visualization of the data (thus the higher the LP value, the lower the risk of dying early in the experiment). We used these LP values rather than the relative risk as they most correctly represent the outcome of the survival analysis. As there were five individuals per jar, survival values for the D. magna individuals from the same jar were considered to be depending on the jar in which they were cultured. This jar dependency was integrated in our analysis by defining "jar" as a random factor. In a second analysis, we zoomed in on D. magna survival on day 14, as WFCD is known to exert strong virulence effects from this day and further (EBERT et al. 2005), and the final day (day 33) of the experiment. Survival on day 14 and day 33 was analysed using a repeated measures generalized linear model (rmGLM), as measures on experimental jars on day 14 and 33 were not independent ("T" in Table 2). In this rmGLM, survival (number of surviving individuals per jar) was considered to follow a binomial distribution. Additionally, we analysed the number of juveniles produced per experimental jar in a generalized linear model (GLM), with the number of juveniles assumed to follow a Poisson error distribution. However, the model for the number of juveniles produced showed a significant level of over-dispersion, so a quasi-Poisson distribution was used instead. For the time to release the first clutch we used a Cox proportional hazards model by using the $\operatorname{coxph}()$ specification in R. We chose this model instead of a traditional ANOVA as the Cox proportional hazards model includes individuals that did not reproduce at the end of the experiment (day 33). The outcome of this analysis generates a linear predictor, which relates to the "reproduction hazard", i.e., the chance to reproduce early in the experiment. As these values most correctly represent the outcome of the Cox survival analysis, we used these values for the visual representation of the data. For each model, we used the AIC criterium to select the best subset of parameters. Post-hoc comparisons between the parasite treatments were made for means within one food quality treatment (when the parasite $\times$ food quality interaction effect was significant) or for means averaged over the food quality treatments (when there was no parasite $\times$ food quality interaction but a significant main parasite effect). Post-hoc comparisons were made using the glht $\{$ multcomp $\}$ function with the mcp = "Tukey" specification in R. 


\section{Results}

An increased degree of nutrient limitation significantly reduced Daphnia survival and reproduction (Fig. 1, Table 2). The overarching survival analysis revealed a significant effect of altered food quality on D. magna survival (Fig. 1), but we found no effects for the parasite treatment (no main parasite effect and no parasite $\mathrm{x}$ food quality interaction effect; Table 2). In general, the impact of P. ramosa or WFCD on host survival was low to absent (Fig. 2). When we zoomed in on the two selected time points (day 14 and day 33), we did find a significant main parasite effect (Fig. 2, Table 2), with individuals infected with $P$. ramosa having a significantly higher survival than individuals from the mixed infection treatment (significant post-hoc difference between means for P.ramosa and mixed infection treatment, averaged over both food quality treatments and time points: $p=0.0018 . z=-3.59$ ). This main parasite effect was mainly driven by the significant differences in survival at extreme food limitation at day 14 (Fig. 3B, see further). When survival was considered for these two time points, we found a significant parasite $\mathrm{x}$ food quality $\mathrm{x}$ time interaction effect (significant $\mathrm{FQ} \times \mathrm{P} \times \mathrm{T}$ interaction in Table 2). For each of these time points, there was no difference in host survival in response to the parasite infection at a low level of food limitation (Fig. 3A, 3C; non-significant post hoc comparisons between each of the parasite treatments exposed to a low level of food limitation). However, at day 33 of the experiment and low food limitation, there was a synergistic effect under multiple parasite exposure, given that the expected survival under the assumption of additive effects was higher than the observed survival (Fig. 3C). When food limitation increased, we did detect a difference in the way parasites impacted host survival. At day 14 and extreme food limitation, individuals infected with P. ramosa had a significantly higher survival than did individuals from the mixed infection treatment (significant post-hoc difference between $P$. ramosa and mixed infections for the extreme food limitation treatment at day $14, \mathrm{p}=0.016, \mathrm{z}=-3.375$ ). At this time point and food quality treatment, exposure to both parasites interacted synergistically to decrease host survival, given that the expected survival under the assumption of additive effects was higher than

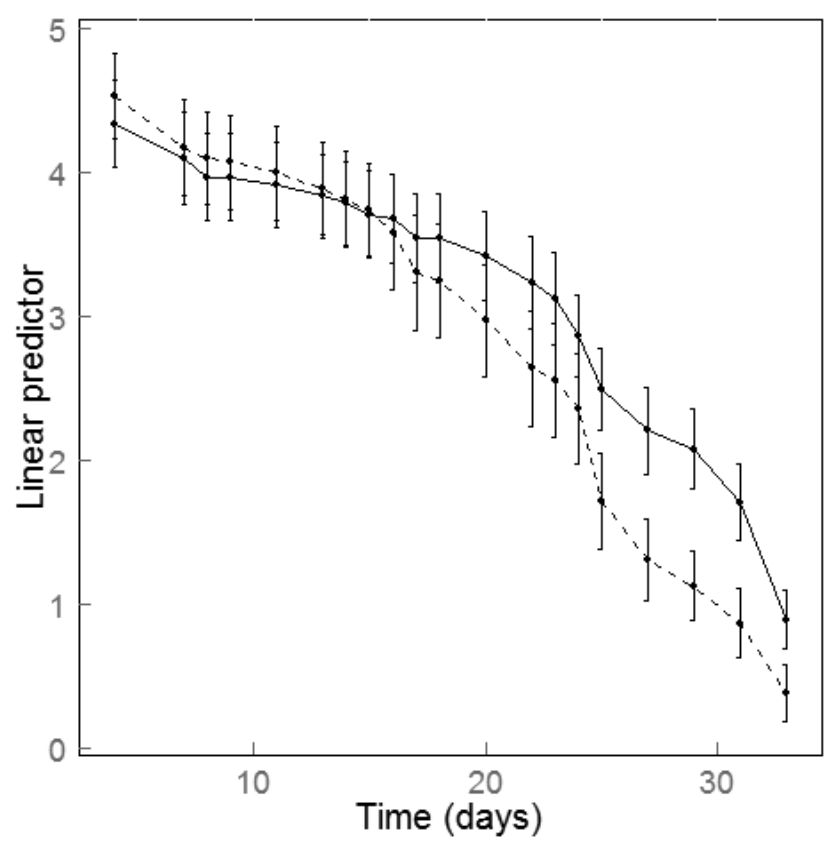

Figure 1 - Linear predictor given for each Daphnia magna individual, in response to the age of Daphnia individual (time in days) and the different degrees of food limitation: limited (L, full line) and extremely limited (EL, dashed line). The value of the linear predictor is inversely related to the risk to death, i.e., the higher value for the linear predictor, the lower the risk to death. Error bars represent $\pm 2 \times \mathrm{SE}, \mathrm{n}=$ 40. Data for the different time points within the same food quality treatment were considered as repeated measures and were included accordingly in the statistical analysis. 
the observed survival under multiple parasite exposure (Fig. 3B). At the final day of the experiment (day 33) and high food limitation, survival was $0 \%$ for the WFCD treatment and lower compared to the placebo and the other parasite treatments (Fig. 3D), although post-hoc comparisons between the different parasite treatments for this food quality treatment at day 33 were never significant. Because of the complete mortality in the WFCD treatment, the expected survival under the assumption of additive parasite exposure effects amounted to $0 \%$ (Fig. 3D). However, there was no difference in the observed survival in the multiple parasite exposure compared to the placebo and P. ramosa treatment after 33 days.

Reproductive output was low during the experiment (total number of juveniles produced per jar in the placebo treatment: 2.8 ; WFCD: 2.35 ; P. ramosa: 1.52 ; WFCD + P. ramosa: 4.55 ), but we found a positive effect of parasites on the number of offspring produced and the time to release the first clutch (Table 2, Fig. 4). Hosts exposed to a single parasite species did not reproduce more or at a different time point compared to the placebo treatment; exposure of the host to the two parasites simultaneously did, however, shift the time to commence reproduction to an earlier time point, which increased the number of offspring produced: there was a significant post-hoc effect comparing D. magna individuals under multiple parasite exposure versus single $P$. ramosa exposure with respect to the time to commence reproduction and the number of offspring (significant post-hoc comparisons between means for $P$. ramosa and mixed infection treatment, averaged over both food quality treatments, for time to commence reproduction: $\mathrm{z}=2.573, \mathrm{p}=0.049$; and for number of offspring produced: $\mathrm{z}=-3.041, \mathrm{p}=0.012$; Fig. 4A-B). The observed reproductive output in the multiple parasite exposure treatment was significantly higher than expected when considering the single parasite exposure effects (Fig. 4A). Increasing nutrient limitation also impacted the number of offspring produced with $D$. magna individuals reproducing less at high nutrient limitation (from $3.65 \pm 0.56$ juveniles at low nutrient limitation to $1.92 \pm 0.41$ juveniles at high nutrient limitation, significant algal culture treatment effect in Table 2). There was, however, no

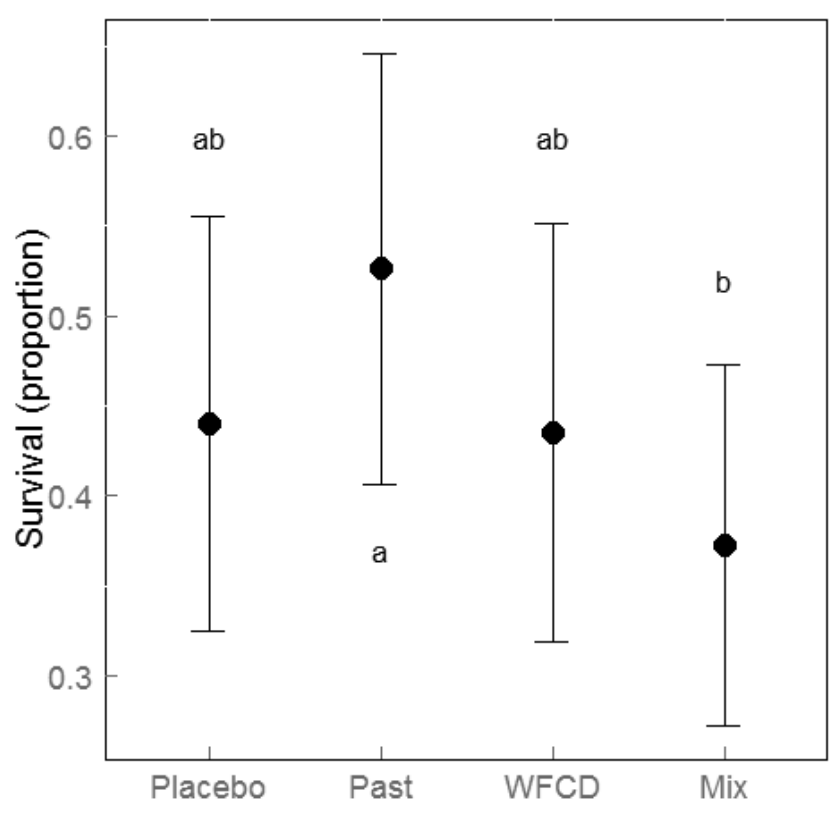

Figure 2 - Proportion of surviving individuals for the different parasite treatments. Values are mean values over two different time points (day 14 and day 33 of the experiment) and the two food quality treatments (limited and extremely limited food quality). Day 14 was chosen as WFCD is known to exert strong virulence effects from this day and further; day 33 as this was the final day of the experiment. Different letters represent significant post-hoc differences. Past $=$ Pasteuria ramosa, $\mathrm{WFCD}=$ White Fat Cell Disease, Mix $=$ Pasteuria ramosa + WFCD treatment. Error bars represent $\pm 2 \times \mathrm{SE}, \mathrm{n}=20$. 
A

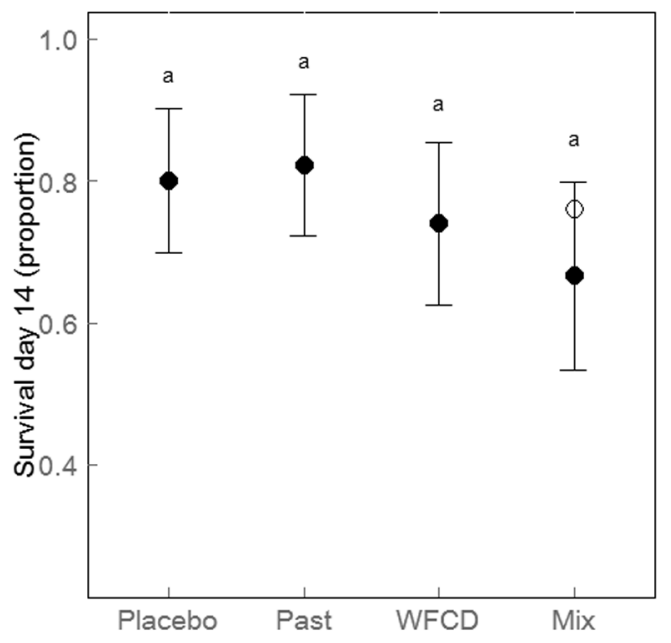

C

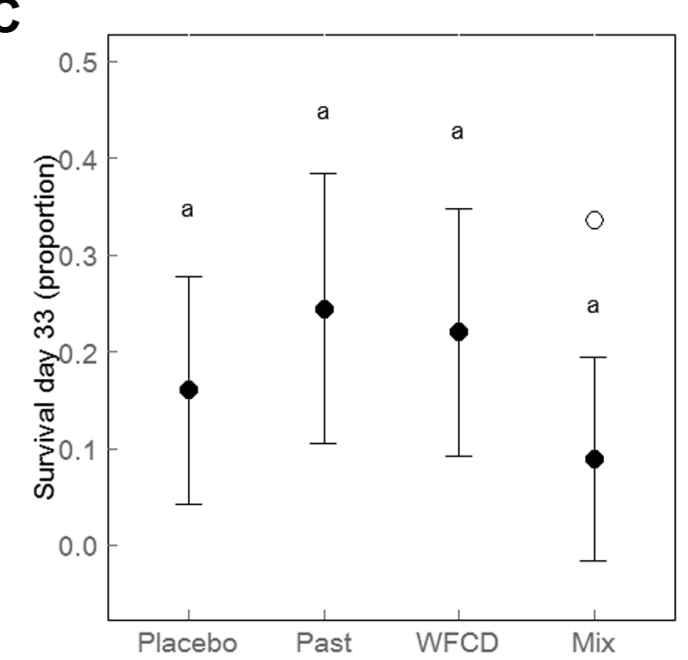

B

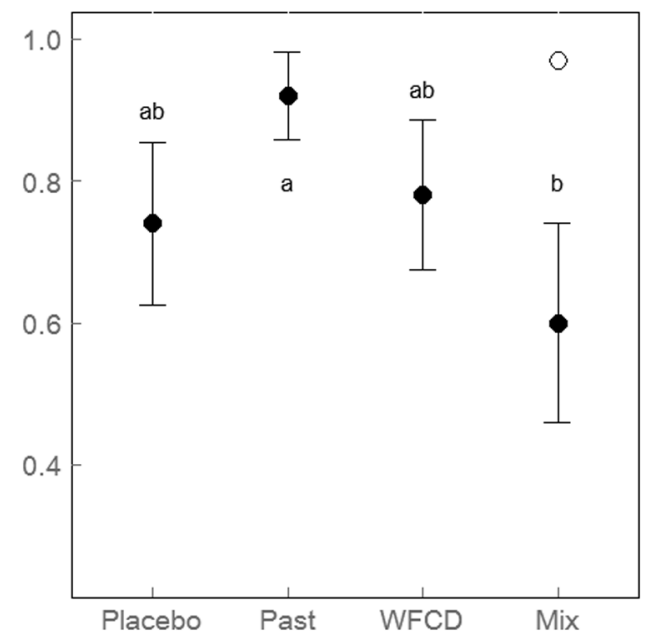

D

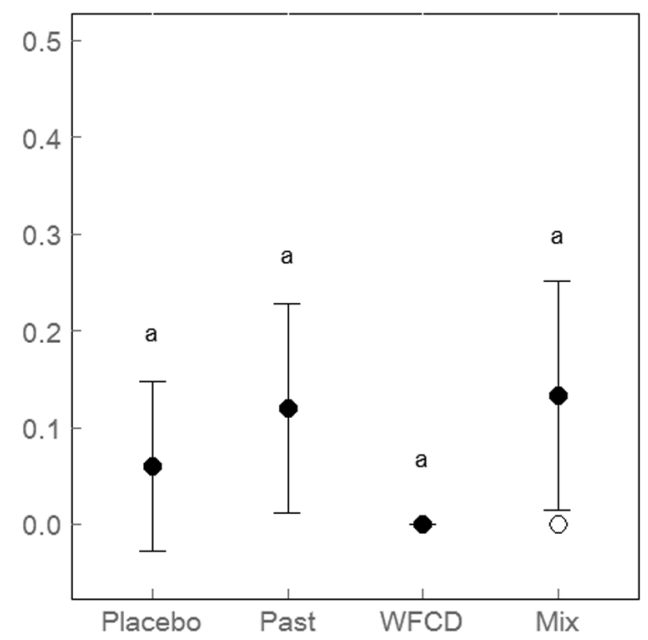

Figure 3 - Proportion of surviving individuals at different time points in the experiment (upper panels A and B: survival after 14 days, lower panels C and D: survival after 33 days) and in the different algal treatments (left panels A and C: highest food quality, right panels B and D: lowest food quality - most extreme nutrient limitation). Day 14 was chosen as WFCD is known to exert strong virulence effects from this day and further; day 33 as this was the final day of the experiment. Error bars represent \pm 2 SE, $n=$ 10. Different letters represent significant post-hoc differences. Open circles represent estimated survival in the combined treatment under the assumption of additive effects of the single parasite treatments (see Material and methods: 'Prediction of joint effects of parasites'). Past $=$ Pasteuria ramosa, WFCD = White Fat Cell Disease, Mix = Pasteuria ramosa + WFCD treatment.

Figure 4 (next page) - Reproductive parameters for Daphnia related to the parasite treatment. A: Number of offspring produced per jar (each jar containing five individuals). B: Timing to release the first cluch, expressed as the linear predictor. The value of the linear predictor relates to the chance that first reproduction occurs early. Error bars represent $\pm 2 \mathrm{SE}, \mathrm{n}=20$. Different letters represent significant post-hoc differences. Open circles represent estimated survival in the combined treatment under the assumption of additive effects of the single parasite treatments (see Material and methods: 'Prediction of joint effects of parasites'). Past $=$ Pasteuria ramosa, $\mathrm{WFCD}=$ White Fact Cell Disease, Mix $=$ Pasteuria ramosa + WFCD treatment. 
TABLE 2

Output of statistical analyses on D. magna fitness parameters, specific tests are given in Material and methods. "Time to death" refers to the outcome of the survival analysis, "Time point analysis" refers to the outcome of the repeated measures generalized linear model (see Material and methods). Parameters that were not included in the minimal adequate model are indicated by "NA".

\begin{tabular}{|c|c|c|c|}
\hline & & \multicolumn{2}{|c|}{ Time to death } \\
\hline & df & $\chi^{2}$ & p-value \\
\hline Food quality (FQ) & 1 & 6,99 & 0,0082 \\
\hline Parasite $(\mathrm{P})$ & 3 & 3,99 & 0,26 \\
\hline \multirow[t]{3}{*}{ FQ x P } & 3 & 0,85 & 0,84 \\
\hline & & \multicolumn{2}{|c|}{ Time point analysis } \\
\hline & & $\chi^{2}$ & p-value \\
\hline Food quality (FQ) & 1 & 3,66 & 0,056 \\
\hline Parasite $(\mathrm{P})$ & 3 & 13,06 & 0,0045 \\
\hline FQ $\times$ P & 3 & 4,67 & 0,2 \\
\hline \multirow[t]{3}{*}{ FQ x P x Time } & 4 & 84,36 & $<0.001$ \\
\hline & & \multicolumn{2}{|c|}{ Amount of juveniles } \\
\hline & & $\chi^{2}$ & p-value \\
\hline Food quality (FQ) & 1 & 7,96 & 0,005 \\
\hline Parasite $(\mathrm{P})$ & 1 & 11,95 & 0,007 \\
\hline \multirow[t]{3}{*}{ FQ $\times$ P } & 3 & NA & NA \\
\hline & & \multicolumn{2}{|c|}{ Time to first reproduction } \\
\hline & & $\chi^{2}$ & p-value \\
\hline Food quality (FQ) & 1 & NA & NA \\
\hline Parasite $(\mathrm{P})$ & 1 & 9,03 & 0,03 \\
\hline FQ x P & 3 & NA & NA \\
\hline
\end{tabular}

A

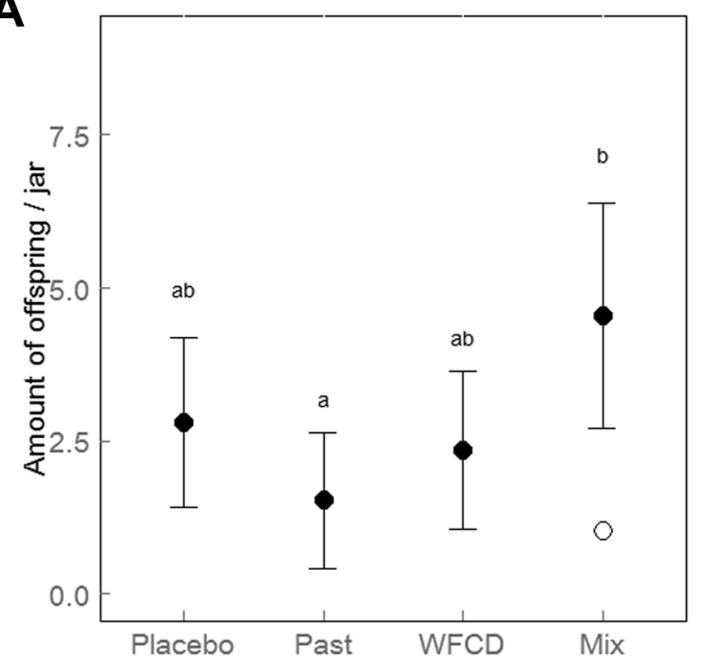

B

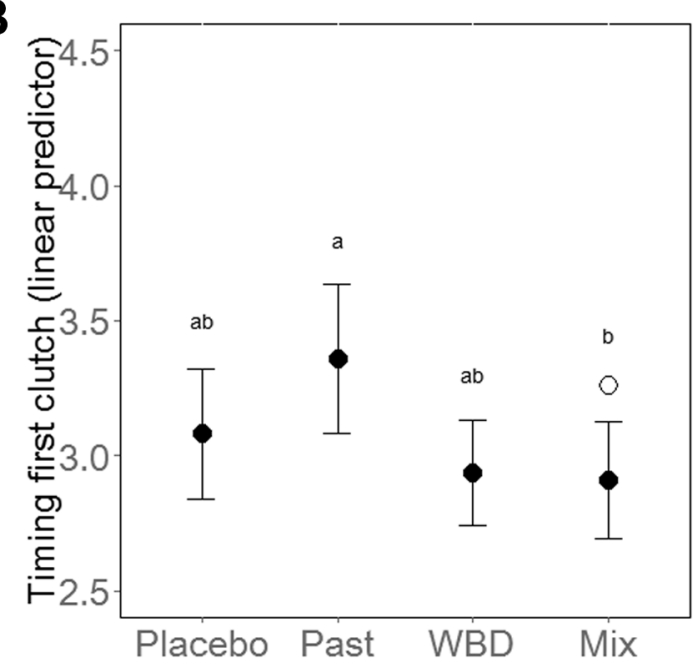


significant interaction between the type of parasite used and the degree of nutrient limitation for both reproductive variables (Table 2 ).

\section{Discussion}

Our study confirms that a reduced food quality negatively affects host reproduction and survival, which is in line with earlier studies focusing on the food quality - host - parasite triad (FROST et al. 2008; CORNET et al. 2014). Additionally, we here show that food quality negatively affects parasite virulence with respect to host mortality upon multiple compared to single parasite exposure. Although both our food quality treatments were always limiting to a certain degree, we argue that this lack of a good-condition control does not jeopardize our main conclusion, i.e., that hosts suffer strongly under a strong decrease in food quality upon a double infection treatment compared to a single infection treatment. Virulence effects in the highest food quality treatment were small to absent, but parasite-induced effects were more pronounced when nutrient limitation was more severe and/or under multiple parasite species exposure, depending on the considered time point in the experiment. This result is in line with many studies that show that parasite virulence resembles the virulence of the most virulent competitor or increases under co-infection (BEN-AMI et al. 2008; SCHMID-HEMPEL 2011; AlizON et al. 2013; GRIFFITHS et al. 2015). However, we here show that this especially occurs upon food quality (nutrient) manipulation. However, the higher parasite-induced mortality in the multiple parasite exposure treatment was not reflected in decreased reproduction, given that this treatment was associated with an earlier time to start to reproduce and a higher reproductive output in the D. magna host.

Both P. ramosa and WFCD are virulent parasites and most likely have a high energy demand to support parasite growth, assuming that the rate at which parasites extract Daphnia nutrients equates with their virulence (EBERT et al. 2004; SMITH \& Holt 1996; Mideo 2009; CRESSler et al. 2014). In this study, single parasite species' effects on Daphnia survival and reproduction were minor (even positive) for P. ramosa. It was mainly WFCD that caused the increased mortality, given that under high nutrient limitation and at day 14 of the experiment, the multiple parasite exposure treatment resulted in a significantly lower survival than did the single P. ramosa exposure treatment. Furthermore, WFCD exposure was associated with $100 \%$ mortality by the last day of the experiment. By the last day, the observed mortality in the multiple parasite exposure was significantly lower than the expected mortality $(100 \%)$. Although this appears to contrast at first sight with our expectations of increased virulence in the multiple parasite treatment, this effect is probably due to the mortality effect induced in the WFCD treatment, combined with the low level of variation for the response (given that overall survival was low).

The stronger mortality effect for WFCD than for P. ramosa can be linked to a difference in infection and exploitation strategies of the two parasites. Expression of parasite virulence depends on a basic level of energy reserve of the host and the parasite to maintain its growth (SMITH \& HOLT 1996; MidEO 2009; CRESSLER et al. 2014). Immunological mechanisms in the host reduce this basic energy level and thus reduce the energy available for the parasite. Simultaneously, parasite loss rates increase with increasing host immunological responses and thus level up the amount of energy needed to induce a successful infection (HALL et al. 2009). The low energy level of the D. magna individuals might have resulted in a failure to establish an infection for P. ramosa. Important to note is that the individuals of Daphnia in this experiment were always nutrient limited to some degree, which is reflected in the low overall fecundity. As such, we assume that there was strong resource competition between the hosts and parasites, in which it was difficult for the parasites to exploit host resources and as a result infections did not get well established. However, WFCD is probably a more efficient parasite when energy provision in the environment and in the host is low. WFCD causes strong phenotypic changes in the adipose tissue, while $P$. ramosa infects the hemolymph and sterilizes its host. Affecting the adipose tissue suggests that the parasite boosts the immune system, but at the same time also retrieves energy from it, in both cases a costly process for the host that may be associated with the high parasite-induced mortality. 
This may also explain why WFCD always induces field infections early in the season, when food is limited due to fast growing populations of Daphnia sp., whereas P. ramosa can only establish infections later in the growing season when food is often not limiting (DECAESTECKER et al. 2005; SCHOEBEL et al. 2014). Equally as for P. ramosa, HALL et al. (2009) found that the outbreak of a fungal epidemic (Metschnikowia bicuspidata) in Daphnia was delayed when the food quality in the environment was low. Nevertheless, under non-limited conditions (i.e. where food quantity and quality is high), causing chronic infections and retrieving resources from the reproductive system, as $P$. ramosa does, is also an efficient strategy in natural populations (EBERT et al. 2004; DECAESTECKER et al. 2005, 2015).

Under the combined infection of P. ramosa with WFCD, D. magna individuals also shifted their reproduction forward. Some organisms do this when subjected to stressful conditions, in an attempt to increase fitness when resources are not yet completely depleted. Such a reproduction shift has been observed several times in Daphnia sp. under stressful conditions, e.g., predation (STIBOR 1992), temperature increase (GEERTS et al. 2014), metal contamination (LOPES et al. 2004). This "fecundity compensation" has also been identified for Daphnia sp.-parasite interactions (CHADWICK \& LITTLE 2005; COOPMAN et al. 2014; LANGE et al. 2014). This can again be linked to an energy allocation perspective. When nutrients are limiting, organisms allocate energy towards increased reproduction and growth rate, but at the cost of survival (BOGGS 2009; PIETRZAK et al. 2010).

\section{Conclusions}

Understanding the factors that determine and interfere with virulence expression in multiple infections is essential for the prediction and control of infectious diseases. Here, we show that the degree of nutrient limitation drives the outcome of multiple parasite exposure, most probably by interfering with the host stoichiometry, energy allocation and its immune system. As infectious diseases are becoming more prominent, it is important to get more insight into this host-pathogen-food quality interaction, which will help in the understanding and management of disease systems in natural populations. It is essential to consider the complete framework of host and parasite community and food web dynamics (DECAESTECKER et al. 2015; AALTO et al. 2015). Our study contributes to the understanding of these interactions by indicating that multiple infections induce synergistic effects, but that the effect is dependent upon the parasite species and trait considered.

\section{Acknowledgements}

We thank Luc De Meester and Steven Declerck for stimulating discussions. Funding was provided by the research projects Belspo IAP project SPEEDY P7/4, the research projects FWO G060216N \& G064313N, the Centre of Excellence SEEDS PF/2010/007 of the KULeuven Research Fund, FWO 1509513N.

\section{References}

Aalto S.L., Decaestecker E. \& Pulkkinen K. (2015). A three-way perspective of stoichiometric changes on host-parasite interactions. Trends in Parasitology 31: 333-340. https://doi.org/10.1016/j. pt.2015.04.005

ABU KWAIK Y. \& BUMANN D. (2013). Microbial quest for food in vivo: 'Nutritional virulence' as an emerging paradigm. Cellular Microbiology 15: 882-890. https://doi.org/10.1111/cmi.12138

ACHARYA S., KYle M. \& ElSER J.J. (2004). Biological stoichiometry of Daphnia growth: An ecophysiological test of the growth rate hypothesis. Limnology and Oceanography 49: 656-665. https:// doi.org/10.4319/10.2004.49.3.0656

Alizon S., DE RoOdE J.C. \& Michalakis Y. (2013). Multiple infections and the evolution of virulence. Ecology Letters 16: 556-567. https://doi.org/10.1111/ele.12076 
ANDERSEN T. \& HESSEN D.O. (1991). Carbon, nitrogen, and phosphorus content of freshwater zooplankton. Limnology and Oceanography 36: 807-814. https://doi.org/10.4319/10.1991.36.4.0807

Bedhomme S., Agnew P., Sidobre C. \& Michalakis Y. (2004). Virulence reaction norms across a food gradient. Proceedings of the Royal Society B: Biological Sciences 271: 739-744. https://doi. org/10.1098/rspb.2003.2657

Ben-Ami F., Mouton L., \& Ebert D. (2008). The effect of multiple infections on the expression and evolution of virulence in a Daphnia-endoparasite system. Evolution 62: 1700-1711. https://doi. org/10.1111/j.1558-5646.2008.00391.x

BEN-Ami F., RigAud T. \& EBERT D. (2011). The expression of virulence during double infections by different parasites with conflicting host exploitation and transmission strategies. Journal of Evolutionary Biology 24: 1307-1316. https://doi.org/10.1111/j.1420-9101.2011.02264.x

BLISS C.I. (1939). The toxicity of poisons applied jointly. Annals of Applied Biology 26: 585-615. https://doi.org/10.1111/j.1744-7348.1939.tb06990.x

BoGGS C.L. (2009). Understanding insect life histories and senescence through a resource allocation lens. Functional Ecology 23: 27-37. https://doi.org/10.1111/j.1365-2435.2009.01527.x

CARius H.J., LitTle T.J. \& EBERT D. (2001). Genetic variation in a host-parasite association: potential for coevolution and frequency-dependent selection. Evolution 55: 1136-1145. https://doi. org/10.1111/j.0014-3820.2001.tb00633.x

CHADWICK W. \& LitTLE T. (2005). A parasite-mediated life-history shift in Daphnia magna. Proceedings of the Royal Society B: Biological Sciences 272: 505-509. https://doi.org/10.1098/rspb.2004.2959

Coopman M. (2014). Context Dependency of host-parasite interactions. PhD thesis, KULeuven, Belgium.

Coopman M., Muylaert K., Lange B., Reyserhove L. \& Decaestecker E. (2014). Context dependency of infectious disease: the cyanobacterium Microcystis aeruginosa decreases White Bacterial Disease in Daphnia magna. Functional Biology 59: 714 - 723. https://doi.org/10.1111/fwb.12298

COORS A. \& DE MEESTER L. (2008). Synergistic, antagonistic and additive effects of multiple stressors: predation threat, parasitism and pesticide exposure in Daphnia magna. Journal of Applied Ecology 45: 1820-1828. https://doi.org/10.1111/j.1365-2664.2008.01566.x

CORnet S., Bichet C., LARCombe S., FAivre B. \& SorCi G. (2014). Impact of host nutritional status on infection dynamics and parasite virulence in a bird-malaria system. Journal of Animal Ecology 83: 256-265. https://doi.org/10.1111/1365-2656.12113

CotNer J.B., HALl E.K., SCOTT J.T. \& HeldAl M.K. (2010). Freshwater bacteria are stoichiometrically flexible with a nutrient composition similar to seston. Frontiers in Microbiology 1: 132. https://doi. org $/ 10.3389 /$ fmicb. 2010.00132

Cressler C.E., Nelson W.A., Day T. \& McCauley E. (2014). Starvation reveals the cause of infection-induced castration and gigantism. Proceedings of the Royal Society B: Biological Sciences 281: 1-9. https://doi.org/10.1098/rspb.2014.1087

DALLAS T. \& DRAKE J.M. (2014). Nitrate enrichment alters a Daphnia-microparasite interaction through multiple pathways. Ecology and Evolution 4: 243-250. https://doi.org/10.1002/ece3.925

Decaestecker E., Declerck S., De Meester L. \& Ebert D. (2005). Ecological implications of parasites in natural Daphnia populations. Oecologia 144: 382-390. https://doi.org/10.1007/s00442$\underline{005-0083-7}$ 
REYSERHOVE L. et al., Multiple parasitism and food limitation

Decaestecker E., Gaba S., Raeymaekers J.A.M., Stoks R., Van Kerckhoven L., Ebert D. \& De MeEster L. (2007). Host-parasite "Red Queen" dynamics archived in pond sediment. Nature 450: 870-873. https://doi.org/10.1038/nature06291

Decaestecker E., De Gersem H., Michalakis Y. \& Raeymaekers J.A.M. (2013). Damped longterm host-parasite Red Queen coevolutionary dynamics: a reflection of dilution effects? Ecology Letters 16: 1455-1462. https://doi.org/10.1111/ele.12186

Decaestecker E., Verrydt D., De Meester L. \& De Clerck S.A.J. (2015). Parasite and nutrient enrichment effects on Daphnia interspecific competition. Ecology 96: 1421-1430. https://doi. org/10.1890/14-1167.1

DeClerck S.A.J., VAnderstukKen M., Pals A., MuylaerT K. \& De Meester L. (2007). Plankton biodiversity along a gradient of productivity and its mediation by macrophytes. Ecology 88: 2199-2210. https://doi.org/10.1890/07-0048.1

DeMotT W.R. \& VAN DONK E. (2013). Strong interactions between stoichiometric constraints and algal defenses: evidence from population dynamics of Daphnia and algae in phosphorus-limited microcosms. Oecologia 171: 175-186. https://doi.org/10.1007/s00442-012-2404-y

De Senerpont Domis L.N., Elser J.J., Gsell A.S., Huszar V.L.M., Ibelings B.W., Jeppesen E., Kosten S., Mooij W.M., Roland F., Sommer U., Van Donk E., Winder M. \& LÜrling M. (2013). Plankton dynamics under different climatic conditions in space and time. Functional Biology 58: 463482. https://doi.org/10.1111/fwb.12053

Duncan A.B., Agnew P., Noel V. \& Michalakis Y. (2015). The consequences of co-infections for parasite transmission in the mosquito Aedis aegypti. Journal of Animal Ecology 84: 498-508. https:// doi.org/10.1111/1365-2656.12302

DUFFY M.A., JAMES T.Y. \& LONGWORTH A. (2015). Ecology, virulence, and phylogeny of Blastulidium paedophthorum, a widespread brood parasite of Daphnia spp. Applied and Environmental Microbiology 81: 5486-5496. https://doi.org/10.1128/AEM.01369-15

DUNEAU D., LUIJCKX P., RUDER L.F. \& EBERT D. (2012). Sex-specific effects of a parasite evolving in a female-biased host population. BMC Biology 104. https://doi.org/10.1186/1741-7007-10-104

EBERT D. (2005). Chapter 3, some parasites of Daphnia. In: EBERT D. (ed.) Ecology, epidemiology and evolution of parasitism in Daphnia. Bethesda (MD), National Center for Biotechnology information, US. Available from http://www.ncbi.nlm.nih.gov/books/NBK2043 [accessed 24 May 2017].

Ebert D., CARIUs H.J., LitTle T. \& DeCAeSTECKER E. (2004). The evolution of virulence when parasites cause host castration and gigantism. American Naturalist 164: S19-S32. https://doi.org/10.1086/424606

ElSer J.J., STABLeR B.L. \& HASSETT P.R. (1995). Nutrient limitation of bacterial growth and rates of bacterivory in lakes and oceans: a comparative study. Aquatic Microbial Ecology 9: 105-110. https:// doi.org/10.3354/ame009105

Elser J.J., Brien W.J.O., Dobberfuhl D.R. \& Dowling T.E. (2000). The evolution of ecosystem processes: growth rate and elemental stoichiometry of a key herbivore in temperate and arctic habitats. Journal of Evolutionary Biology 13: 845-853. https://doi.org/10.1046/j.1420-9101.2000.00215.x

Elser J.J., Acharya K., Kyle M., Cotner J., Makino W., Markow T., Watts T., Hobbie S., Fagan W., SCHADE J., HOOD J. \& STERNER R.W. (2003). Growth rate-stoichiometry couplings in diverse biota. Ecology Letters 6: 936-943. https://doi.org/10.1046/j.1461-0248.2003.00518.x

ESWARAPPA S.M., ESTRELA S. \& BROWN S.P. (2012). Within-host dynamics of multi-species infections: facilitation, competition and virulence. PLOS ONE 7: e38730. https://doi.org/10.1371/journal. pone. 0038730 
Fellous S. \& Koella J.C. (2009). Infectious dose affects the outcome of the within-host competition between parasites. American Naturalist 173: E117-E184. https://doi.org/10.1086/598490

FERGUSON H.M. \& READ A.F. (2002). Genetic and environmental determinants of malaria parasite virulence in mosquitoes. Proceedings of the Royal Society B: Biological Sciences 269: 1217-1224. https://doi.org/10.1098/rspb.2002.2023

Frost P.C., Benstead J.P., Cross W.F., Hillebrand H., Larson J.H., Xenopoulos M.A. \& YoshidA T. (2006). Treshold elemental ratios of carbon and phosphorus in aquatic consumers. Ecology Letters 9: 774-779. https://doi.org/10.1111/j.1461-0248.2006.00919.x

Frost P.C., EBERT D. \& SMITH V.H. (2008). Responses of a bacterial pathogen to phosphorus limitation of its aquatic invertebrate host. Ecology 89: 313-318. https://doi.org/10.1890/07-0389.1

GeERTS A., De MeEsTER L. \& StOKs R. (2014). Heat tolerance and its evolutionary potential along a latitudinal gradient in Daphnia magna. Evolutionary Ecology Research 16: 517-528.

GRAHAM A.L. (2008). Ecological rules governing helminth-microparasite coinfection. PNAS, 105: 566-570. https://doi.org/10.1073/pnas.0707221105

Griffiths E.C., Pedersen A.B., Fenton A. \& Petchey O.L. (2015). Analysis of a summary network of co-infection in humans reveals that parasites interact most via shared resources. Proceedings of the Royal Society B - Biological Sciences 281. https://doi.org/10.1098/rspb.2013.2286

Hall S.R., Simonis J.L., Nisbet R.M., Tessier A.J. \& CACERes C.E. (2009). Resource ecology of virulence in a planktonic host-parasite system: an explanation using dynamic energy budgets. American Naturalist 174: 149-162. https://doi.org/10.1086/600086

HESSEN D.O. \& LYCHE A. (1991). Inter- and intraspecific variations in zooplankton element compostion. Archiv für Hydrobiologie 121: 343-353.

IZHAR R., ROUTTU J. \& BEN-AMi F. (2015). Host age modulates within-host parasite competition. Biology Letters 11: 20150131. https://doi.org/10.1098/rsbl.2015.0131

Jansen M., Stoks R., Decaestecker E., Coors A., VAn De Meutter F. \& De Meester L. (2010). Local exposure shapes spatial patterns in infectivity and community structure of Daphnia parasites. Journal of Animal Ecology 79: 1023-1033. https://doi.org/10.1111/j.1365-2656.2010.01718.x

JEYASINGH P.D., WEIDER L.J. \& SteRneR R.W. (2009). Genetically-based trade-offs in response to stoichiometric food quality influence competition in a keystone aquatic herbivore. Ecology Letters 12: 1229-1237. https://doi.org/10.1111/j.1461-0248.2009.01368.x

Kapari L., Haukioja E., Rantala M.J. \& RuUhola T. (2006). Defoliating insect immune defense interacts with induced plant defense during a population outbreak. Ecology 87: 291-296. https://doi. org/10.1890/05-0362

Klemola N., Klemola T., Rantala M.J. \& Ruuhola T. (2007). Natural host- plant quality affects immune defence of an insect herbivore. Entomologia Experimentalis et Applicata 123: 167-176. https:// doi.org/10.1111/j.1570-7458.2007.00533.x

Lafferty K.D., Allesina S., Arim M., Briggs C.J., De Leo G., Dobson A.P., DunNe A.J., Johnson P.T.J., Kuris A.M., Marcogliese D.J., Martinez N.D., Memmott J., Marquet P.A., McLaughlin J.P., Mordecai E.A., Pascual M., Poulin R. \& Thieltges D.W. (2008). Parasites in food webs: the ultimate missing links. Ecology Letters 11: 533-546. https://doi.org/10.1111/j.1461-0248.2008.01174.x

Lambrechts L., Chavatte J.-M., Snounou G. \& Koella J.C. (2006). Environmental influence on the genetic basis of mosquito resistance to malaria parasites. Proceedings of the Royal Society B: Biological Sciences 273: 1501-1506. https://doi.org/10.1098/rspb.2006.3483 
Lange B., Reuter M., Ebert D., Muylaert K. \& Decaestecker E. (2014). Diet quality determines interspecific parasite interactions in host populations. Ecology and Evolution 4: 3093-3102. https://doi. org/10.1002/ece3.1167

LitTle T.J. \& Killick S.C. (2007). Evidence for a cost of immunity when the crustacean Daphnia magna is exposed to the bacterial pathogen Pasteuria ramosa. Journal of Animal Ecology 76: 12021207. https://doi.org/10.1111/j.1365-2656.2007.01290.x

LOPES I., BAIRD D.J. \& RiBEIRO R. (2004). Genetic determination of tolerance to lethal and sublethal copper concentrations of field populations of Daphnia longispina. Archives of Environmental Contamination and Toxicolocy 46: 43-51. https://doi.org/10.1007/s00244-003-2143-5

Mideo N. (2009). Parasite adaptations to within-host competition. Trends in Parasitology 25: 261-268. https://doi.org/10.1016/j.pt.2009.03.001

Metzger C.M.J.A, Luijckx P., Bento G., Mariadassou M. \& Ebert D. (2016). The Red Queen lives: Epistatis between linked resistance loci. Evolution 70: 480-487. https://doi.org/10.1111/evo.12854

OJALA K., JULKUnEN-TiitTo R., LindSTRÖM L. \& MAPPES J. (2005). Diet affects the immune defence and life-history traits of an Arctiid moth Parasemia plantaginis. Evolutionary Ecology Research 7: $1153-1170$.

PEDERSON A.B. \& FENTON A. (2007). Emphasizing the ecology in parasite community ecology. Trends in Ecology and Evolution 22: 133-139. https://doi.org/10.1016/j.tree.2006.11.005

Penczykowski R.M., LANE A.L. \& Koskella B. (2016). Understanding the ecology and evolution of host-parasite interactions across scales. Evolutionary Applications 9: 37-52. https://doi.org/10.1111/ eva.12294

Pietrzak B., Grzesiuk M. \& BednARsKa A. (2010). Food quantity shapes life history and survival strategies in Daphnia magna (Cladocera). Hydrobiologia 643: 51-54. https://doi.org/10.1007/s10750$\underline{010-0135-9}$

Ponce-Soto G.Y., Aguirre-von-Wobeser E., Eguiarte L.E., Elser J.J., Lee Z.M.-P. \& SouZA V. (2015). Enrichment experiment changes microbial interactions in an ultra-oligotrophic environment. Frontiers in Microbiology 6: 246. https://doi.org/10.3389/fmicb.2015.00246

PRESTON D.L. \& JOHNSON P.T.J. (2010). Ecological consequences of parasitism. Nature Education Knowledge 3: 47.

Regoes R.R., Hottinger J.W., Sygnarski L. \& Ebert D. (2003). The infection rate of Daphnia magna by Pasteuria ramosa conforms with the mass-action principle. Epidemiology \& Infection 131: 957-966. https://doi.org/10.1017/S0950268803008793

Sarpe D., De Senerpont Domis L.N., Declerck S.A.J., Van Donk E. \& Ibelings B.W. (2014). Food quality dominates the impact of food quantity on Daphnia life history: possible implications for re-oligotrophication. Inland Waters 4: 363-368. https://doi.org/10.5268/IW-4.4.701

SCHMID-HEMPEL P. (2011). Evolutionary parasitology: the integrated study of infection, immunology, ecology and genetics. Oxford University Press, Oxford, United Kingdom.

Schoebel C.N., Auld S.K.J.R., SpaAk P. \& LitTle T.J. (2014). Effects of juvenile host density and food availability on adult immune response, parasite resistance and virulence in a Daphnia-parasite system. PLoS One 9: 1-9. https://doi.org/10.1371/journal.pone.0094569

Seppälä O., Liljeroos K., Karvonen A. \& Jokela J. (2008). Host condition as a constraint for parasite reproduction. Oikos 117: 749-753. https://doi.org/10.1111/j.0030-1299.2008.16396.x

SMith V.H. \& HolT R.D. (1996). Resource competition and within-host dynamics. Trends in Ecology and Evolution 11: 386-398. https://doi.org/10.1016/0169-5347(96)20067-9 
SøndERGAARD M., JENSEN J.P. \& JEPPESEN E. (1999). Internal phosphorus loading in shallow Danisch lakes. Hydrobiologia 408-409: 145-152. https://doi.org/10.1023/A:1017063431437

Sterner R.W., Hagemeier D.W., SMith W.L. \& SMith R.F. (1993). Phytoplankton nutrient limitation and food quality for Daphnia. Limnology and Oceanography 38: 857-871. https://doi.org/10.4319/ $\underline{10.1993 .38 .4 .0857}$

STERNER R.W. (2008). On the phosphorus limitation paradigm for lakes. International Review of Hydrobiology 93: 433-445. https://doi.org/10.1002/iroh.200811068

STIBOR H. (1992). Predator induced life history shifts in a freshwater cladoceran. Oecologia 92: 162165. https://doi.org/10.1007/BF00317358

VAle P.F., Choisy M. \& LitTLE T. (2013). Host nutrition alters the variance in parasite transmission potential. Biology Letters 9: 1-5. https://doi.org/10.1098/rsbl.2012.1145

Verreydt D., De Meester L., Decaestecker E., Villena M.-J., Van Der Gucht K., VANNORMELINGEN P., VyVERMAN W. \& DECleRCK S.A.J. (2012). Dispersal-mediated trophic interactions can generate apparent patterns of dispersal limitation in aquatic communities. Ecology Letters 15: 218-226. https://doi.org/10.1111/j.1461-0248.2011.01728.x

WOLINSKA J., GIESSLER S. \& KOERNER H. (2009). Molecular identification and hidden diversity of novel Daphnia parasites for European lakes. Applied and Environmental Microbiology 75: 7051. https:// doi.org/10.1128/AEM.01306-09

Manuscript received: 8 November 2016

Manuscript accepted: 25 March 2017

Published on: 25 July 2017

Branch editor: Frederik Hendrickx 